\title{
Clinical results of shock wave lithotripsy treatment in elderly patients with kidney stones: Results of 1433 patients
}

\author{
Cevahir Ozer, Mehmet Ilteris Tekin \\ Department of Urology, Baskent University, Adana, Turkey.
}

\begin{abstract}
Summary Objective: In this study, it was aimed to evaluate the efficacy and safety of SWL treatment in elderly patients with kidney stones. Materials and methods: Data from a total of 3024 patients who underwent SWL treatment for urinary tract stone disease in three centers of our university were evaluated retrospectively. A total of 1433 patients in the adult age group treated for single kidney stones were included in the study. The patients were divided into 3 groups (18-40, 41-64 and $\geq 65)$ years depending on their age. Demographic data, stone parameters, stone-free rate (SFR) and clinically insignificant residual fragment (CIRF) rate, number of SWL sessions and complication rate were analyzed according to the age groups.

Results: The mean age of the patients was $47.38 \pm 13.24$ years. Stone size was significantly lower in the 18-40 years age group compared to other groups $(p=0.000)$ and the stones were mostly located on the right side in this age group $(p=0.007)$. There was no significant relationship between age groups and gender, stone localization, and number of SWL sessions.

The overall SFR was $66.4 \%$. Although the SFR was lower (61.4\%) and the rate of multiple sessions (27.2\%) was higher in $\geq 65$ years group, there was no statistically significant difference between age groups regarding SFR, CIRF, need for additional sessions, and complication rates.

Conclusions: Due to its similar clinical results, treatment of SWL should not be ignored as a treatment option in the geriatric patient group with kidney stones.
\end{abstract}

KEY WORDS: Kidney stones; Shock wave lithotripsy; Elderly.

Submitted 14 September 2020; Accepted 27 October 2020

\section{INTRODUCTION}

Urinary stone disease affects individuals, healthcare systems and society due to its high prevalence, recurrent and unpredictable nature and dominance in workingage adults (1). Shock wave lithotripsy (SWL), flexible ureterorenoscopy, and percutaneous nephrolithotomy are the treatment options offered by the recent guidelines for the treatment of patients with kidney stones (24). As SWL is an effective, non-invasive treatment that can be applied without general anesthesia, it remains a current treatment option (5-7)

Although many predictive factors of the success of SWL, such as urinary tract anatomy, severity of concomitant obstruction, body mass index (BMI), stone size, stone density, stone to skin distance and type of SWL device used have been identified, the results regarding the effect of age are contradictory (6-9).

The purpose of this study was to evaluate the efficacy and safety of SWL treatment in elderly patients with kidney stones.

\section{Materials AND METHOdS}

Data from 3024 consecutive patients who underwent SWL treatment for urinary tract stone disease since 2003, in three centers of our university, were evaluated retrospectively. A total of 1433 patients in the adult age group ( $\geq 18$ years old) treated for single kidney stones were included in the study. The SWL decision was determined by patient and doctor preference. Informed consent was obtained from all patients.

Before the procedure, all patients were evaluated by routine blood and urine analysis, plain abdominal radiography, renal ultrasonography (US), intravenous urography and/or non-contrast computed tomography (CT). SWL was not applied in the presence of pregnancy, aortic aneurysm, morbid obesity (BMI $\geq 40$ ), bleeding diathesis, active urinary infection and non-functional kidney on the side of the stone.

Lithostar Modularis Uro-plus (Siemens Medical Systems, Erlangen, Germany), an electromagnetic lithotripter, was used in all three centers for the SWL procedure. The procedure was applied to all patients under sedoanalgesia. After the procedure, oral analgesics were recommended to all patients.

The results of the procedure were evaluated using kidneys, ureters and bladder (KUB) radiography, US and/or CT performed 3 months after the SWL treatment.

Data interpretation and statistical analysis

The patients were divided into 3 groups (18-40 years, 41-64 years and $\geq 65$ years) depending on their age. Demographic data, stone parameters, stone-free rate (SFR) and CIRF rate, number of SWL sessions and complication rate were analyzed according to age groups. The presence of stones less than $4 \mathrm{~mm}$ was considered as clinically insignificant residual stone (10).

The data were analyzed using the Statistical Package of Social Science (Version 25.0; SPSS Inc., Chicago, IL, USA). Comparisons between groups were applied using OneWay ANOVA test. The catagorical variables between the groups was analyzed by using the Chi square test. Only significant variables were included in the multiple 
regression analysis. Values of p less than 0.05 were considered statistically significant.

\section{RESULTS}

The mean age of the patients was $47.38 \pm 13.24$ years. Stone size was significantly lower in the 18-40 age group compared to the other groups $(\mathrm{p}=0.000)$ and in this age group, the stones were mostly located on the right side in this age group $(p=0.007)$. There was no significant difference between the age groups regarding gender, stone localization, and number of SWL sessions (Table 1).

The overall SFR was $66.4 \%$. Although SFR was lower $(61.4 \%)$ and the rate of multiple sessions $(27.2 \%)$ was higher in the $\geq 65$ years group, there was no statistically significant difference between the age groups regarding SFR, CIRF, need for additional sessions, and complication rates (Table 1). Since there was only a significant difference in stone size between the groups, it was evaluated by multiple regression analysis, but no significant regression model was obtained.

Mortality due to SWL procedure was not observed in any patient. Steinstrasse was observed in $22(1.5 \%)$ patients. Its distribution by age groups was $6(1.3 \%)$ patients in $18-40$ years group, 14 (1.7\%) in 41-64 years group and $2(1.3 \%)$ in $\geq 65$ years group. Subcapsular hematoma was seen only in 1 patient in the 41-64 years group. One of the 2 patients whose operation was terminated due to arrhythmia was in the 18-40 years group and the other in the $\geq 65$ years group. Hospitalization was required due to pain in 1 patient and fever in another patient in the 41-64 years group. In the 18-40 years group, 1 patient developed pancreatitis and 1 patient developed urinoma.

There was no statistically significant difference between age groups and complication rates (Table 1).

\section{Table 1.}

Characteristic features and clinical outcomes of patients.

\begin{tabular}{|c|c|c|c|c|c|}
\hline & Total & $18-40$ years & 41-64 years & $\geq 65$ years & $\mathrm{p}$ \\
\hline$\overline{\text { Number }(\%)}$ & $1433(100)$ & $448(31.3)$ & $827(57.7)$ & $158(11.0)$ & \\
\hline$\overline{\text { Gender }(\mathrm{n}, \%)}$ & & & & & 2.77 \\
\hline Male & $882(61.5)$ & $286(63.8)$ & $506(61.2)$ & $90(57.0)$ & \\
\hline Female & 551 (38.5) & $162(36.2)$ & $321(38.2)$ & $68(43.0)$ & \\
\hline$\overline{\text { Stone size }(\mathrm{mm})}$ & $11.99 \pm 5.52$ & $10.88 \pm 5.00$ & $12.43 \pm 5.66$ & $12.80 \pm 5.78$ & 0.000 \\
\hline$\overline{\text { Side }(n, \%)}$ & & & & & 0.007 \\
\hline Right & $693(48.3)$ & $244(54.5)$ & $377(45.5)$ & $72(45.6)$ & \\
\hline Left & $740(51.7)$ & $204(45.5)$ & $450(55.5)$ & $86(55.4)$ & \\
\hline Localization (n, \%) & & & & & 0.688 \\
\hline Upper pole & $171(11.9)$ & $61(13.6)$ & $90(10.9)$ & $20(12.7)$ & \\
\hline Middle calyx & $166(11.6)$ & $50(11.2)$ & $94(11.4)$ & $22(14.0)$ & \\
\hline Lower pole & $375(26.2)$ & $110(24.6)$ & $226(27.3)$ & $39(24.8)$ & \\
\hline Pelvis & $721(50.3)$ & $227(50.7)$ & $417(50.4)$ & $77(45.5)$ & \\
\hline Number of sessions $(n, \%)$ & & & & & 0.065 \\
\hline 1 & 1119 (78.1) & $364(81.3)$ & $640(77.4)$ & $115(72.8)$ & \\
\hline$\geq 2$ & $314(21.9)$ & $84(18.7)$ & $187(22.6)$ & $43(27.2)$ & \\
\hline \multicolumn{6}{|l|}{ Outcome (n, \%) } \\
\hline Stone-free & 951 (66.4) & $306(68.3)$ & $548(66.3)$ & $97(61.4)$ & 0.285 \\
\hline CIRF & $297(20.7)$ & $92(20.5)$ & $172(20.8)$ & $33(20.9)$ & 0.674 \\
\hline$\overline{\text { Complication }(n, \%)}$ & $29(2.0)$ & $9(2.0)$ & $17(2.1)$ & $3(1.9)$ & 0.991 \\
\hline
\end{tabular}

\section{Discussion}

SWL remains one of the treatment methods for the management of kidney stones. Treatment of kidney stones in elderly patients can be complicated by comorbid conditions. This makes SWL treatment a good option for elderly patients, since it can be applied in an outpatient setting without general anesthesia.

In several previous studies, it has been reported that the success rates of SWL treatment decreased in elderly patients $(10,11)$. In a retrospective study of 472 diseases conducted by Gokce et al., no difference was found between age groups and success rates of SWL (6). In a study by Chen et al., the SFR in elderly patients were found similar to that of non-elderly patients $(41.1 \%$ vs 46.5\%) (12). In our study, both SFR and CIRF rate among age groups were similar. The fact that the parameters in the evaluation of treatment success such as different age groups ( $>60$ years, $\geq 65$ years and $>/ \geq 70$ years) definition of success (stone-free, stone-free plus CIRF), definition of CIRF ( $\leq 2 \mathrm{~mm}$ and $\leq 4 \mathrm{~mm}$ ), time to evaluate success ( 1 month, 3 months) and evaluation method of treatment result (one or more of KUB graphy, US, CT) are not homogeneous makes it difficult to comment on this issue $(6,8,10,12-15)$.

Chen et al. found that the rate of retreatment in elderly patients who received SWL for kidney stones was similar to that of non-elderly patients $(38.6 \%$ vs $42.9 \%, \mathrm{p}=$ 0.485 ) (12). In our study, this rate was $27.2 \%$ and there was no statistically significant difference between the other age groups.

The frequency of major complications associated with SWL in the elderly population is between $0 \%$ and $5.6 \%$ $(6,12-14,16)$. In our study, this rate is $1.9 \%$ and is consistent with the literature. Whether the incidence of complications associated with SWL in the elderly population is higher than the non-elderly population is controversial. While Chen et al. had a higher risk of complications in patients $\geq 65$ years, Gokce et al. did not find any significant difference $(6,12)$. In our study, we did not find any difference between age groups in terms of complication rates. We believe that the lack of difference may result from the patient selection bias and SWL techniques.

As in our study, the use of electromagnetic lithotriptors in the treatment of kidney stones with SWL provides better pain management (17). We think that better pain management can increase the success rate and reduce the complication rate by providing a better focus of the stone. The prominent limitations of this study are its retrospective nature and lack of some predictive parameters such as urinary tract anatomy, severity of concomitant obstruction, BMI, stone size due to its retrospective nature. However, the large number of patients is the strength of this study.

\section{Conclusions}

Our results suggest that there is no relationship between the clinical results of SWL treatment and age. Due to its similar clinical results, treatment of SWL with similar clinical results should not be ignored as a treatment option in the geriatric patient group with kidney stones. 


\section{ACKNOWLEDGEMENTS}

The authors would like to thank Cagla Sariturk, Baskent University, Adana Dr. Turgut Noyan Medical and Research Center, Biostatistics Unit.

\section{References}

1. Morgan MS, Pearle MS. Medical management of renal stones. BMJ. 2016; 352:i52.

2. Turk C, Petrik A, Sarica K, et al. EAU Guidelines on interventional treatment for urolithiasis. Eur Urol. 2016; 69:475-482.

3. Assimos D, Krambeck A, Miller NL, et al. Surgical management of stones: American Urological Association/Endourological Society guideline, part II. J Urol. 2016; 196:1161-1169.

4. Pradere B, Doizi S, Proietti S, et al. Evaluation of guidelines for surgical management of urolithiasis. J Urol. 2018; 99:1267-1271.

5. Knoll T, Buchholz N, Wendt-Nordahl G. Extracorporeal shockwave lithotripsy vs. percutaneous nephrolithotomy vs. flexible ureterorenoscopy for lower-pole stones. Arab J Urol. 2012; 10:336341.

6. Gokce MI, Akinci A, Akpinar C, et al. Comparison of efficacy of shock wave lithotripsy in different age groups. Journal of Urological Surgery. 2017; 4:66-70.

7. Kocakgol H, Yilmaz AH, Yapanoglu T, et al. Efficacy and predictive factors of the outcome of extracorporeal shock wave lithotripsy: a review of one-thousand-nine-hundred-ninety-seven patients. Journal of Urological Surgery. 2019; 6:207-212.

8. Abdel-Khalek M, Sheir KZ, Mokhtar AA, et al. Prediction of success rate after extracorporeal shock-wave lithotripsy of renal stones--a multivariate analysis model. Scand J Urol Nephrol. 2004; 38:161-167.
9. Ichiyanagi O, Nagaoka A, Izumi T, et al. Age-related delay in urinary stone clearance in elderly patients with solitary proximal ureteral calculi treated by extracorporeal shock wave lithotripsy. Urolithiasis. 2015; 43:419-426.

10. Abe T, Akakura K, Kawaguchi M, et al. Outcomes of shockwave lithotripsy for upper urinary-tract stones: a large-scale study at a single institution. J Endourol. 2005; 19:768-773.

11. Kimura M, Sasagawa T. Significance of age on prognosis in patients treated by extracorporeal shock wave lithotripsy. Nihon Hinyokika Gakkai Zasshi. 2008; 99:571-577.

12. Chen YZ, Lin WR, Lee CC, et al. Comparison of safety and outcomes of shock wave lithotripsy between elderly and non-elderly patients. Clin Interv Aging. 2017; 12:667-672.

13. Philippou P, Lamrani D, Moraitis K, et al. Shock-wave lithotripsy in the elderly: Safety, efficacy and special considerations. Arab J Urol. 2011; 9:29-33.

14. Sighinolfi MC, Micali S, Grande M,et al. Extracorporeal shock wave lithotripsy in an elderly population: how to prevent complications and make the treatment safe and effective. J Endourol. 2008; 22:2223-2226.

15. $\mathrm{Ng} \mathrm{CF}$, Wong A, Tolley D. Is extracorporeal shock wave lithotripsy the preferred treatment option for elderly patients with urinary stone? A multivariate analysis of the effect of patient age on treatment outcome. BJU Int. 2007; 100:392-395.

16. Polat F, Yesil S, Ak E, et al. Safety of ESWL in elderly: evaluation of independent predictors and comorbidity on stone-free rate and complications. Geriatr Gerontol Int. 2012; 12:413-417.

17. Bianchi G, Marega D, Knez R, et al. Comparison of an electromagnetic and an electrohydraulic lithotripter: Efficacy, pain and complications. Arch Ital Urol Androl. 2018; 90:169-171.

\section{Correspondence}

Cevahir Ozer, MD

cevahirozer@gmail.com

Mehmet Ilteris Tekin, MD

ilterist@hotmail.com

Department of Urology, Baskent University, Adana (Turkey) 